NBSIR 75-755

\title{
The CPSC Road Test of Bicycle Braking Performance - Experimental Evaluation
}

Donald E. Marlowe

Engineering Mechanics Section

Mechanics Division

Institute for Basic Standards

National Bureau of Standards

Washington, D. C. 20234

August 1975

Final

Prepared for

Office of Consumer Product Safety

Center for Consumer Product Technology

Institute for Applied Technology

National Bureau of Standards

Washington, D. C. 20234 


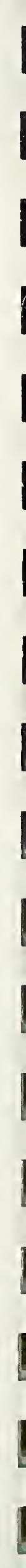


NBSIR 75.755

THE CPSC ROAD TEST OF BICYCLE

BRAKING PERFORMANCE -

EXPERIMENTAL EVALUATION

Donald E. Marlowe

Engineering Mechanics Section

Mechanics Division

Institute for Basic Standards

National Bureau of Standards

Washington, D. C. 20234

August 1975

Final

Prepared for

Office of Consumer Product Safety

Center for Consumer Product Technology

Institute for Applied Technology

National Bureau of Standards

Washington, D. C. 20234

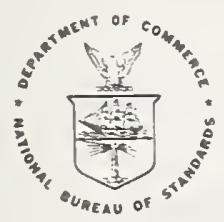

U.S. DEPARTMENT OF COMMERCE, Rogers C.B. Morton, Secretary James A. Baker, III, Under Secretary

Dr. Betsy Ancker-Johnson, Assistant Secretary for Science and Technology

NATIONAL BUREAU OF STANDARDS, Ernest Ambler, Acting Director 


\section{CONTENTS}

Page

1. SCOPE

1.1 Test Purpose

1.2 Test Equipment

1.3 Test Flow

2. APPARATUS

2.1 Handbrake Lever Loading Fixture

2.2 Ground Marker System

2.3 Timer

3. TEST CONDITIONS

3.1 Test Surface

3.2 Rider

4. PROCEDURE

4.1 Set-up for Primary Handbrake Lever

4.2 Set Up for Extension Hand Brake Lever

4.3 Set Up for Coaster Brake Systems

4.4 Testing

4.4.1 Handbrake Loading Test

4.4.2 Rocking Test

4.4.3 Performance Test

6. DISCUSSION

6.1 Loading and Rocking Test 7

6.2 Braking Test 7

6.3 Coefficient of Friction and Effect of Pavement Surface 8

6.4 Rider Reaction Times

6.5 Effect of Rider Weight

8. REFERENCES 


\section{LIST OF FIGURES}

Figure 1 - Flow Diagram for Handbrake Tests

Figure 2 - Handbrake Loading Fixture

Figure 3 - Loading Apparatus on a Bicycle

Figure 4 - Ground Marker System

Figure 5 - Velocity-Timer Apparatus

Figure 6 - Loading Apparatus Clamp on Brake Lever

Figure 7 - Firing Switch for Coaster Brakes

Figure 8 - Braking Test Data Sheet

Figure 9 - Bicycle Performance Test Sample Calculation 


\title{
THE CPSC ROAD TEST OF \\ BICYCLE BRAKING PERFORMANCE - EXPERIMENTAL EVALUATION \\ Donald E. Marlowe
}

\begin{abstract}
The brake performance criteria to be published as part of a mandatory regulation on bicycle safety requirements has been evaluated. Fifteen bicycles were tested in accordance with the regulation. A mathematical adjustment of the actual test speed of the bicycle to $24 \mathrm{~km} / \mathrm{hr}$ ( $15 \mathrm{mph}$ ) is necessary before the weight allowance can be made to the stopping distance in the evaluation of these tests. A danger of injury to the test rider exists during the tests and future efforts should be made toward replacement of these tests with a simpler laboratory procedure.
\end{abstract}

Key Words: Bicycles; braking; consumer safety; handbrake; safety; testing.

\section{SCOPE}

Accident reports received by the Consumer Product Safety Commission list many injuries to children as a result of accidents involving bicycles. Many of these injuries result from the inability of the bicycle to stop quickly in an emergency situation. As a result, the Comission has included a series of handbrake performance criteria in the mandatory regulation on bicycle safety requirements which they have prepared.

\subsection{Test Purpose}

This report describes tests which were performed at the National Bureau of Standards as a partial evaluation of the braking tests called for in the Federal Bicycle Safety Regulation, Requirements for Bicycles, July 16, 1974 [1]. These tests included the Loading Test $(1512.18(d)(2)(i))$ the Rocking Test (1512.18(d)(2)(iii)) and the Performance Test (1512.18 (d) $(2)(v))$.

*The numbers in parentheses refer to paragraphs of the proposed regulation. 


\subsection{Test Equipment}

The test equipment assembled for these tests included a force gage, handbrake loading assembly, an electronic timer for measurement of bicycle velocity, a ground position marker gun assembly and a level paved surface upon which to perform the tests.

\subsection{Test Flow}

The flow of procedures followed in these tests is shown in Figure 1.

\section{APPARATUS}

\subsection{Handbrake Lever Loading Fixture}

A loading fixture (Figure 2) which incorporates a $445 \mathrm{~N}$ (100 1bf) spring force gage and a gripping linkage for attachment to the brake lever was fabricated for these tests. This apparatus was based on a design which had been developed at the University of Iowa. In use, the apparatus is mounted on the handlebar (Figure 3 ) and grips the brake lever. The rider applies force to the apparatus lever. This lever pushes up on the force gage which is connected through the linkage shown to the brake lever. An engineering drawing of this apparatus is provided in the Appendix. At the instant the rider begins to apply force to the lever, a switch on the force gage is closed and the ground marker system is actuated. A second switch could be actuated at a predetermined force level.

\subsection{Ground Marker System}

The marker system is used to indicate on the ground the point at which the brakes were first applied. For these tests, a marker gun designed for use as an automobile driver education aid was modified for mounting on a bicycle. The system (Figure 4) included the double barreled gun, a twelve volt battery, the switches mounted on the loading assembly, the marker cartridges which are supplied with the gun, and the wiring necessary to connect the switch, gun, and battery in series. The marker cartridges contained a yellow, quick drying paint. During the tests reported here, for the bicycles equipped with handbrakes, a first cartridge was fired at the instant brakes were applied and a second at the instant the applied force equaled $178 \mathrm{~N}$ (40 1bf). The distance between the two marks so produced was used to estimate the rider's actuation time for the system. In addition, several tests were conducted with a second, nominally identical gun system mounted on the bicycle. This system was wired to the opposite side loading assembly and could be used to estimate the left-hand-right-hand coordination of the brake levers. 
For the tests on bicycles equipped with a coaster brake, the marker system was actuated by the backward motion of the drive chain as the brake was applied (Figure 7 ).

The batteries used to actuate the solenoid in this system posed a special problem. In the use for which the solenoid fired gun was designed, the power from an automobile battery is used, and is continuously recharged. In this application, the first tests were made using two, 6 volt lantern batteries connected in series. These quickly discharged to a point where they would no longer actuate the solenoid and had to be replaced. This often occurred before testing could be completed on one bicycle. To eliminate this problem, a rechargeable 12 volt battery used to start a walk behind lawn mower was chosen. The battery had enough capacity to allow the testing of up to 3 bicycles before it needed recharging.

\subsection{Timer}

An electronic timer, capable of measuring the elapsed time between two similar events to within one microsecond, was used to record the time interval between passage of the bicycle wheels over a tape switch on the ground. Knowing the elapsed time and the wheel base of the bicycle, the velocity of the bicycle could be calculated. The equipment used is shown in Figure 5. It shows the timer, a $1.5 \mathrm{~m}$ ( $5 \mathrm{ft}$ ) long ground tape switch, and a battery to power the switch circuit.

\section{TEST CONDITIONS}

\subsection{Test Surface}

The test surface required for these tests is a dry, clean, level, paved surface of a length adequate to accommodate the bicycle during the performance test. For these tests, an outdoor asphalt parking lot approximately $90 \mathrm{~m}$ (300 ft) long was used. The measured slope of this surface was 0.3 percent. To compensate for the effects which this slope and prevailing winds might have on the average stopping distance, alternate braking tests were made in opposite directions across the timing strip. Before any tests were conducted, any moisture which might have accumulated on the surface during the previous night was allowed to dry. The coefficient of static friction was measured between this surface and the tire of one bicycle included in this program. This will be discussed in section 6.3 .

\subsection{Rider}

As has been realized from the beginning of these tests, the largest variable is probably the test rider. While the tangible effects of his weight on stopping distance can be allowed for, other rider related effects such as reaction time, agility, anticipation and confidence 
have not been well quantified. Several measurements were made during these tests in an effort to define reaction time and agility (the ability to coordinate left-hand-right-hand brake actuation). The problem of rider confidence, or lack of it, has so far defied numerical measurement. Five riders have tested bicycles for this program. Several bicycles were tested by more than one rider. A discussion of these tests will be given later. It should be noted here, however, that every rider crashed at least one bicycle. For this reason, all test riders should be equipped with suitable safety equipment, including a helmet, to minimize the injuries possible during an accident.

\section{PROCEDURE}

The following is a detailed description of the procedure followed during testing in accordance with paragraph 1512.18 (d) of the proposed regulation:

1) Assemble the bicycle according to the instructions provided by the manufacturer.

2) Inflate the tires to the pressure molded into the tire sidewall. Record the tire pressure.

3) The test rider should ride the bicycle to familiarize himself with its behavior in the various gear ratios and under rapid braking conditions.

4) Determine the bicycle payload by weighing the on-bicycle test equipment and rider. Record the weights.

5) Measure and record the wheel base of the bicycle. This measurement is made from the center of the front axle to the center of the rear axle.

\subsection{Set-up for Primary Handbrake Lever}

1) Adjust the position of the brake lever on the handlebar so that the lever will be pulled vertically by the action of the force gage during testing. This may involve changing the location of the levers on the handlebars such that they are generally below the lowest part of the handlebar (Figure 6).

2) Tighten the clamp to the lever, $25 \mathrm{~mm}$ (1 in) from the lever end (Figure $6)$.

3) Adjust the stops on the force gage to apply a maximum of $178 \mathrm{~N}$ ( 40 lbf) to the brake lever. If the clamp bottoms against the handlebar, 
at a load less than $178 \mathrm{~N}$ (40 lbf), adjust the position of the clamp on the lever to insure that the lever bottoms against the handlebar.

4) Adjust the length of the linkage from the force gage to the clamp so that the brake system is fully relaxed and no braking forces are being applied to the brake levers.

5) Tighten the clamp of the force gage to the handlebar.

6) Make a final adjustment of the brakes according to the operating instructions. No further brake adjustments are allowed by the regulation after this adjustment $(1512.18(d)(2))$.

7) Install the ground marker gun on the front fork of the bicycle (Figure 4). Strap the battery to the bicycle.

8) Connect the battery to the marker gun switches and guns.

9) Photograph the bicycle with the test hardware mounted on the bicycle.

10) Wipe the braking surface of the tire rims with alcohol to remove any residue from earlier bicycle use.

\subsection{Set Up for Extension Hand Brake Lever}

1) Adjust the position of the extension lever on the handlebar so that the lever will be pulled vertically by the action of the fingers during testing.

2) Install the firing switch on the extension lever and the ground marker gun on the fork.

3) Make a final brake adjustment according to the manufacturer's operating instructions.

4) Install the battery and necessary wiring.

5) Photograph the bicycle with the test hardware mounted on the bicycle.

6) Wipe the braking surface of the tire rims with alcohol to remove any residue from earlier bicycle use.

\subsection{Set Up for Coaster Brake Systems}

1) Install the ground marker gun on the bicycle fork.

2) Install the firing switch on the seat tube so that the chain reversal caused by the braking action causes the switch to catch in the chain, and actuate the switch (Figure 7 ). 
3) Install the battery and necessary wiring.

4) Photograph the bicycle.

\subsection{Testing}

The following tests shall be performed on all bicycles. The test sequence will be in accordance with the flow diagram (Figure 1). For a detailed procedure for bicycle brake testing see a Procedure for Testing Bicycle Braking Performance [2]. A sample data sheet for recording the braking test information is shown in Figure 8 .

4.4.1 Handbrake Loading Test

On all bicycles equipped with handbrake levers and/or extension levers, perform the Handbrake Loading $(1512.18(d)(2)(i))$ by applying $445 \mathrm{~N}(100 \mathrm{lbf})$ to the brake levers or by bottoming the hand levers against the handlebars, whichever comes first. This test may require removal of the stops on the force gage (Figure 6) to allow full travel of the gage. This load shall be applied and removed 10 times.

\subsubsection{Rocking Test}

On all bicycles equipped with handbrake levers and/or extension levers, perform the Rocking Test (1512.18(d)(2)(iii)) by placing the test rider on the bicycle and, with the brakes loaded as in the Loading Test, drag the bicycle 6 times forward and 6 times rearward for a distance of $75 \mathrm{~mm}$ ( 3 inches) each way.

\subsubsection{Performance Test}

1) Set the stops on the force gages to $178 \mathrm{~N}$ (40 1bf) applied to the brake lever and adjust the switches on the marker guns so that the guns fire upon first actuation of the brake levers and at $178 \mathrm{~N}$ (40 lbf) or the maximum load.

2) Set up the elapsed timer and triggering tape switch on the test pavement.

3) Load the ground marker guns.

4) Conduct stopping runs according to the Handbrake Performance Test $(1512.18(\mathrm{~d})(2)(\mathrm{v}))$ while traveling in opposite directions across the timing switch.

5) Measure the stopping distance from the rearmost ground mark to the corresponding gun on the bicycle. Make the measurement along the original line of travel of the bicycle. Disregard the changes in path line which occur during the test. 
6) Compute the stopping distance, making the corrections for bicycle velocity and payload. A sample calculation is shown in Figure 9.

\section{TEST RESULTS}

The specimen parameters for the 15 bicycles tested are given in Table 1. The stopping distances for the bicycles measured during this evaluation of the test method are given in Table 2. It is estimated that the errors in the measurement of elapsed time did not exceed 0.0001 seconds, and that the errors in stopping distance measurement did not exceed $0.03 \mathrm{~m}(0.1 \mathrm{ft})$.

\section{DISCUSSION}

It should be noted early in this discussion that the apparatus assembled for these tests is not unique. Several alternate ways of measuring the lever forces or bicycle velocity could have been devised.

A further note about rider safety is necessary here. These tests are performed at relatively high speeds on a paved surface. There exists a danger of an accident, resulting in possible injury to the rider. Accidents occurred during testing of four of the fifteen bicycles used in this program. It is significant that every test rider had at least one accident. After these accidents, several of the riders declined to test another bicycle.

\subsection{Loading and Rocking Tests}

In general, the flow (Figure 1 ) and procedures for these two tests and the performance test are not specified in the proposed regulation and evolved during the test evaluation and hardware development period.

All bicycles equipped with handbrakes were tested for compliance with the loading test and rocking test. All bicycles passed these tests with the exception of bicycle 9. One of the brake pads on the front caliper of this bicycle was dislodged from its holder during the rocking test. The pad was replaced in the holder, and the rocking test was repeated with no further failures.

\subsection{Braking Tests}

Tests were performed on 15 bicycles equipped with many of the handbrakefootbrake combinations currently available. A recurrent problem throughout these tests was the difference in equipment and arrangement among the several bicycles. To some extent, every bicycle tested became a separate project. 
As was indicated above in section 4.4.3, the bicycle stopping distance of interest has been interpreted to be the straight line distance from the first ground mark to a point opposite the marker gun along the original line of travel of the bicycle. This distance was chosen instead of the distance along the path over which the bicycle traveled during the stop, because it is the shorter of the two distances and represents the minimum distance needed to stop during an emergency situation. In addition to the measured stopping distance, table 2 shows the stopping distance corrected by adjusting the bicycle speed to 24 $\mathrm{km} / \mathrm{h}(22 \mathrm{fps})$ and the bicycle payload to $68.1 \mathrm{~kg}(150 \mathrm{lb})$.

It was necessary to make the velocity correction because the weight allowance provided for in the regulation assumes that the bicycle is moving at $24 \mathrm{~km} / \mathrm{h}$ (15 mph).

In addition, the percent variation in the corrected stopping distances is shown. Most of the bicycles tested were capable of meeting the acceptance criteria of the regulation after the above two adjustments to the stopping distance had been made. The percent variation in stopping distance after these adjustments ranged from 8 percent to 144 percent. Three bicycles failed to stop from the required speed within $4.5 \mathrm{~m}$ (15 ft).

An analytical study of these and other variables which affect these tests is presently being carried out [3]. This study contributed to these procedures in the areas of data reduction and in the averaging of the effects of weather and pavement. The data from these tests will be used in the evaluation of the analysis.

\subsection{Coefficient of Friction and Effect of Pavement Surface}

A coefficient of friction measurement of two different test surfaces was made using one bicycle. The stopping distance of this bicycle on these surfaces under nominally identical conditions was compared.

The coefficient of friction was measured by locking the rear wheel of the bicycle. With $45.4 \mathrm{~kg}(100 \mathrm{lb})$ of weights placed on the seat, the force exerted on the ground by the rear wheel was measured. A force gage was attached to the rear tire near the ground and a gradually increasing horizontal force was applied until the tire slipped on the pavement. The two surfaces tested in this way were the paved parking lot which was normally used for testing, and an unpainted, smooth concrete laboratory floor. The results of these tests are shown in Table 3.

\subsection{Rider Reaction Times}

As was discussed above, several bicycles were instrumented to measure the brake force application time and the left-right coordination of the brake handles. The results of these tests are given in Table 4. 
These times are within the range of times reported for similar testing at other laboratories.

\subsection{Effect of Rider Weight}

As can be seen from Table 2, two bicycles were tested by several riders of different weights. The results from these tests are inconclusive. While the raw stopping distances tended to be longer for the heavier rider, as expected, the corrected distances did not show such a trend. This can be seen best in the data reported for bicycle 8 tested with extension levers.

\section{CONCLUSIONS}

The tests on brake systems proposed for the mandatory Requirements for Bicycles have been performed on several representative samples. A mathematical adjustment of the actual test speed of the bicycle to $24 \mathrm{~km} / \mathrm{h}$ (15 mph) should be permitted by the regulation before the weight allowance correction is made to the stopping distance for the proper evaluation of the braking performance by these tests. Twenty percent of the specimens failed to stop within the required distance. All of these were equipped with caliper brakes on both wheels. An analytical study which discusses the effect of many variables on stopping distance is being developed. A danger of injury to the test rider exists during the performance tests and future efforts might be made toward replacement of this, and possibly the other brake tests, with a simpler, laboratory procedure. 


\section{REFERENCE S}

The documents which are applicable to these tests include:

1. Requirements for Bicycles, Part 1512, Federal Register, Vo1.39, No. 137, July 16, 1974, and its admendments.

2. Marlowe, D. E., A Procedure for Determining Bicycle Braking Performance, NBSIR 75-953, in preparation.

3. Mordfin, L., The CPSC Road Test of Bicycle Braking Performance - Kinetic and Error Analysis, NBSIR 75-786, in preparation. 


\begin{tabular}{|l|c|c|c|}
\hline $\begin{array}{c}\text { Bicycle Assembly } \\
\text { According to } \\
\text { Manufacturers } \\
\text { Instructions }\end{array}$ & \begin{tabular}{|c|c|} 
Payload \\
Familiarization \\
Ride \\
for Test \\
Rider
\end{tabular} \\
\cline { 2 - 3 }
\end{tabular}

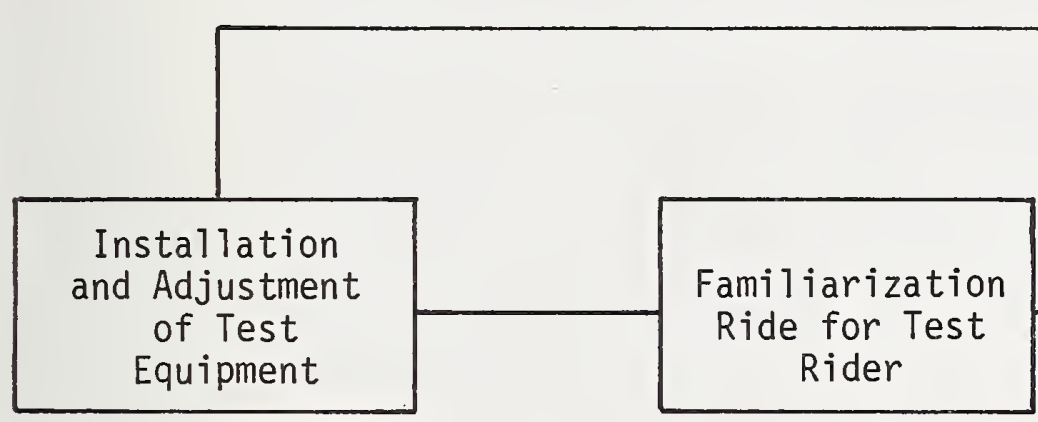

Final Brake Adjustment

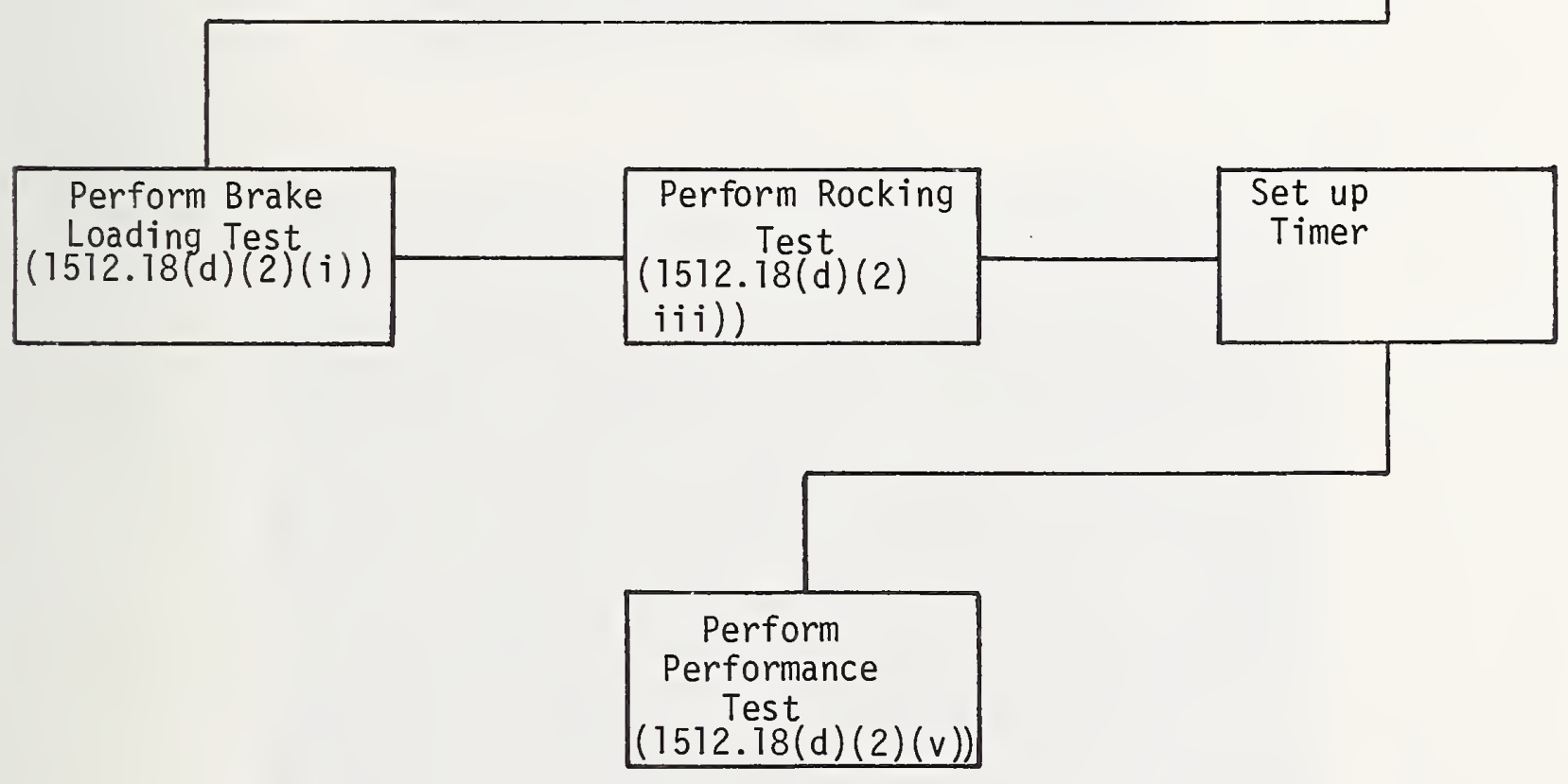

Figure 1 - Flow Diagram for Handbrake Tests 


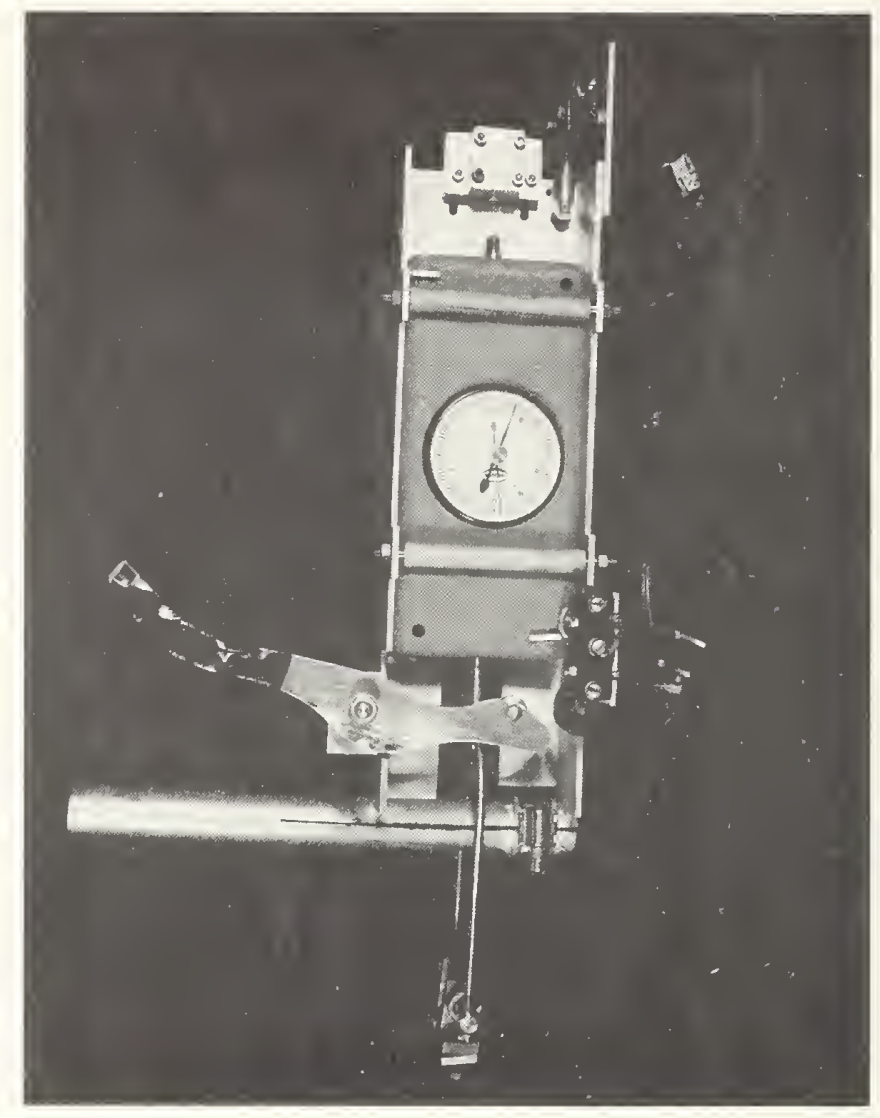

Figure 2 - Handbrake Loading Fixture

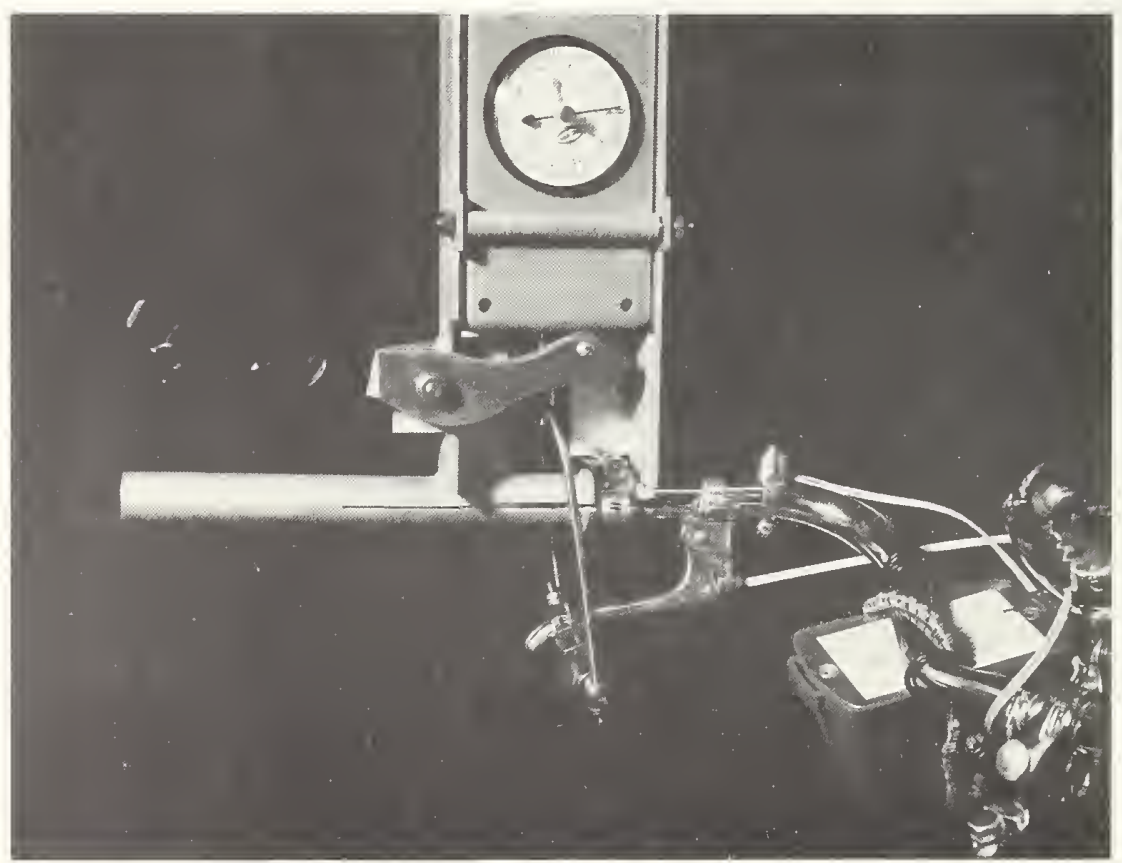

Figure 3 - Loading Apparatus on a Bicycle 


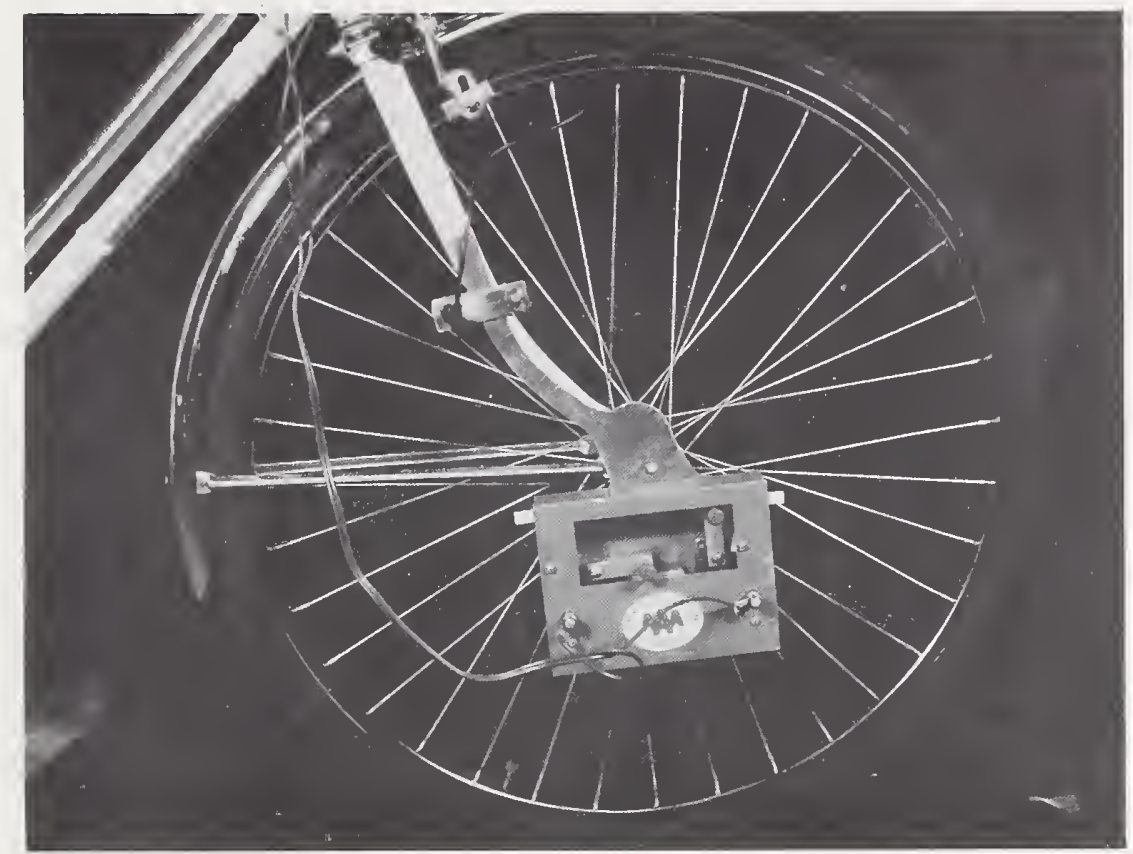

Figure 4 - Ground Marker System

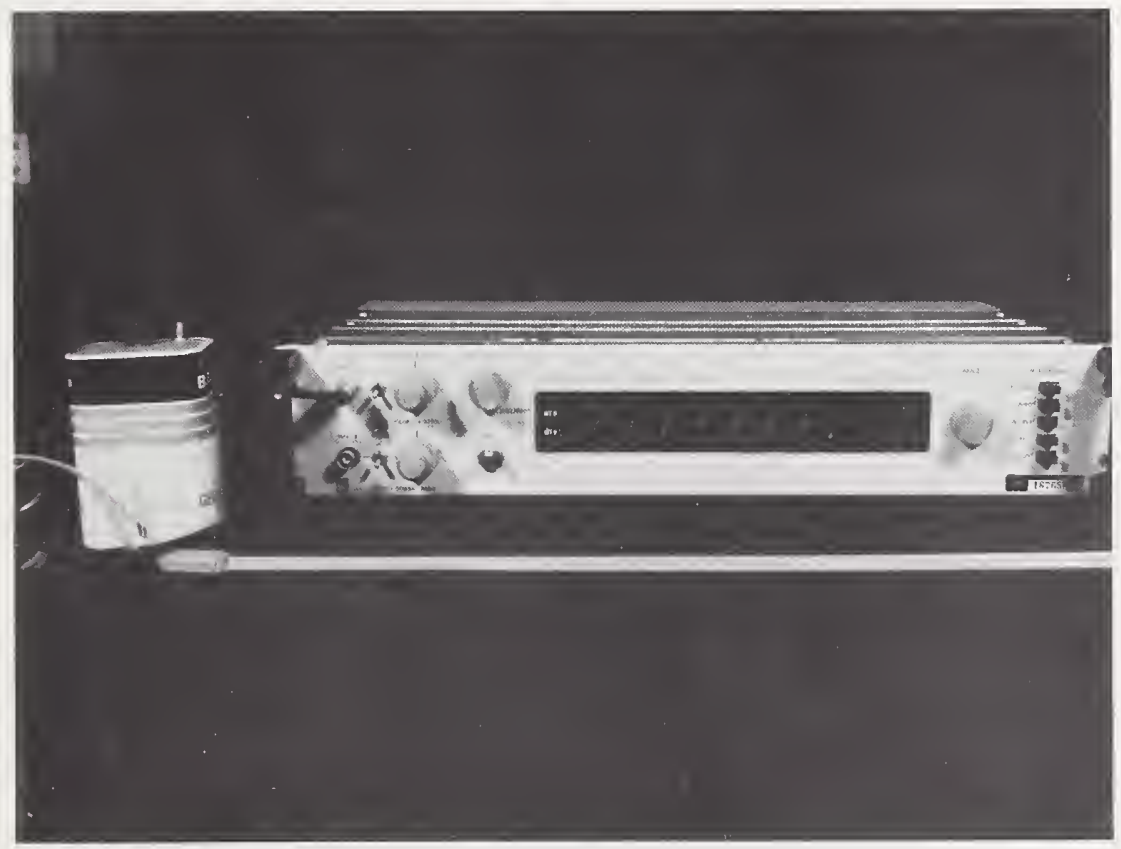

Figure 5 - Velocity-Timer Apparatus 


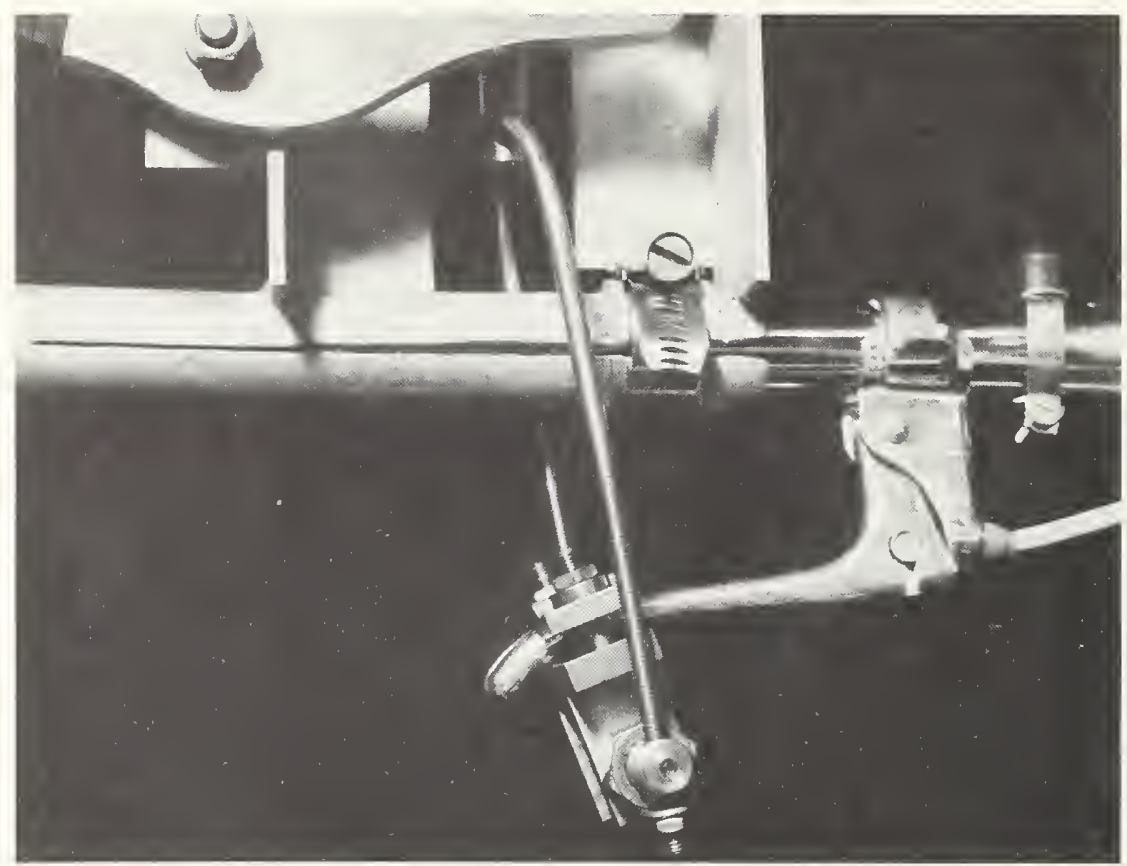

Figure 6 - Loading Apparatus Clamp on Brake Lever

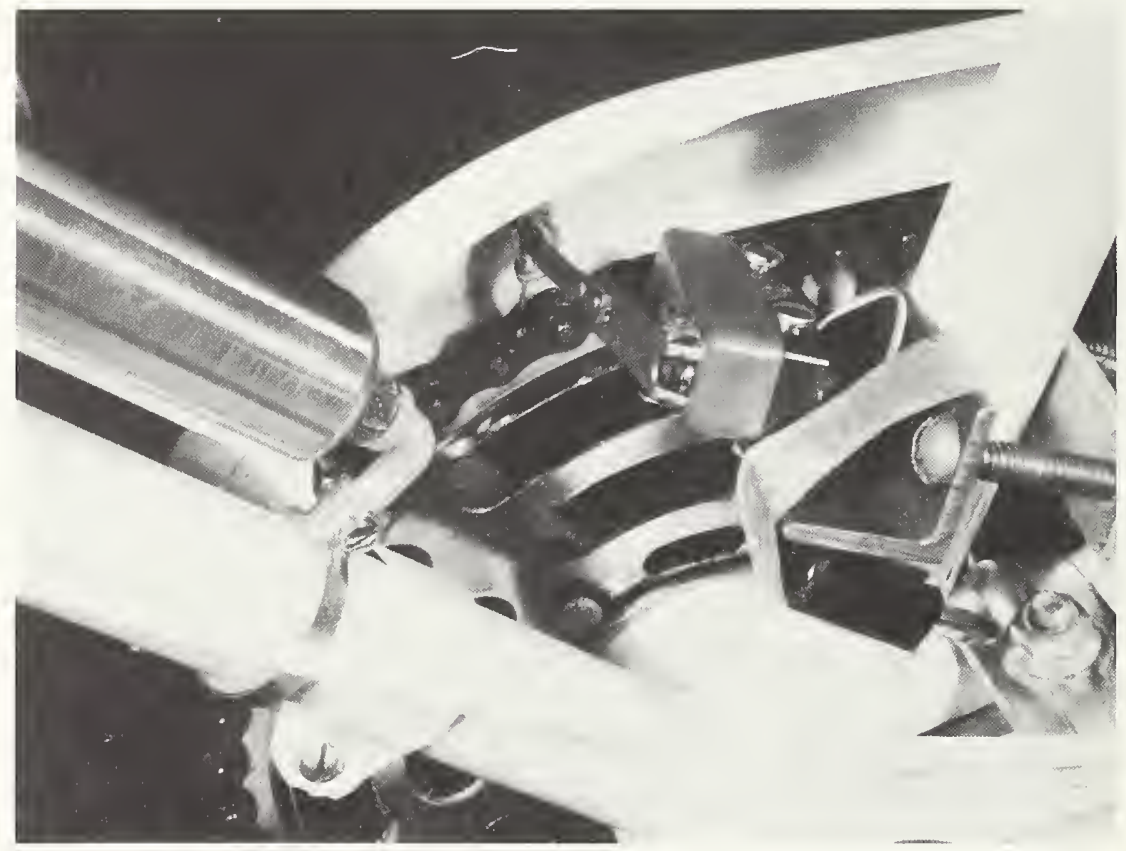

Figure 7 - Firing Switch for Coaster Brakes 
a) Bicycle Manufacturer

Serial No.

Model No.

d) Bicycle Information

Wheel Size

in

Max Gear Ratio

Brake Type

Brake Mfg.

Frame Size

in

f) Loading Test

Load on Force Gage

Lever Hit Bar

Pass-Fai1

h) Performance Test

Elapsed

Time

Run for Speed Direction

No. Measurement of Run sec
$1 \mathrm{bf}$

Stopping

Distance

g) Rocking Test

Pass-Fail e) Test Information

Wheel Base in Equip. Weight lbf Rider Weight lbf from

from Markers

Rear most

Marker

ft
Distance Between

L-R Application

Coordination of $40 \mathrm{lbf}$ skidding

Figure 8 - Braking Test Data Sheet 


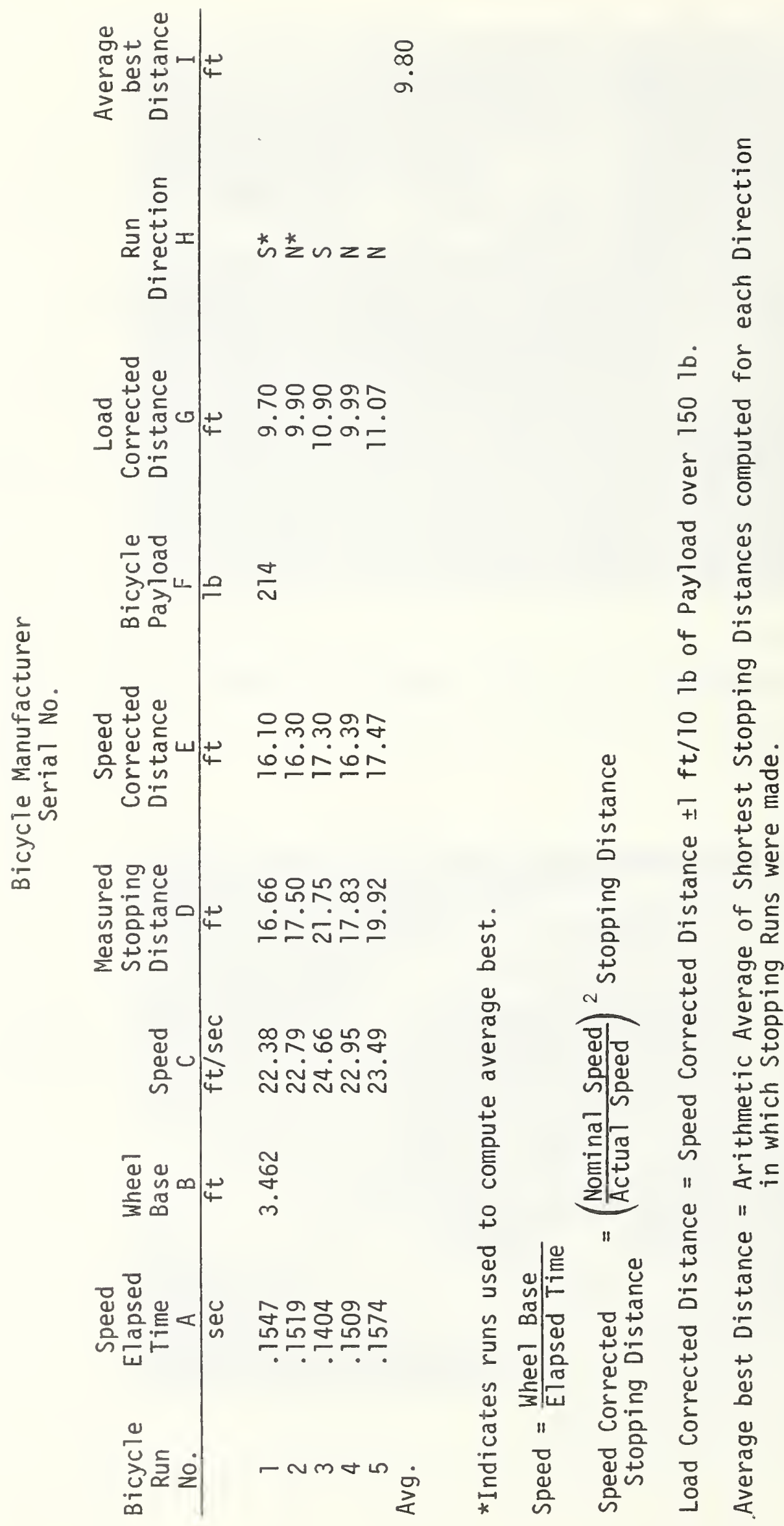

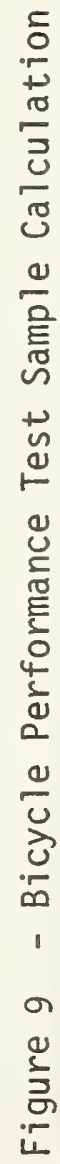




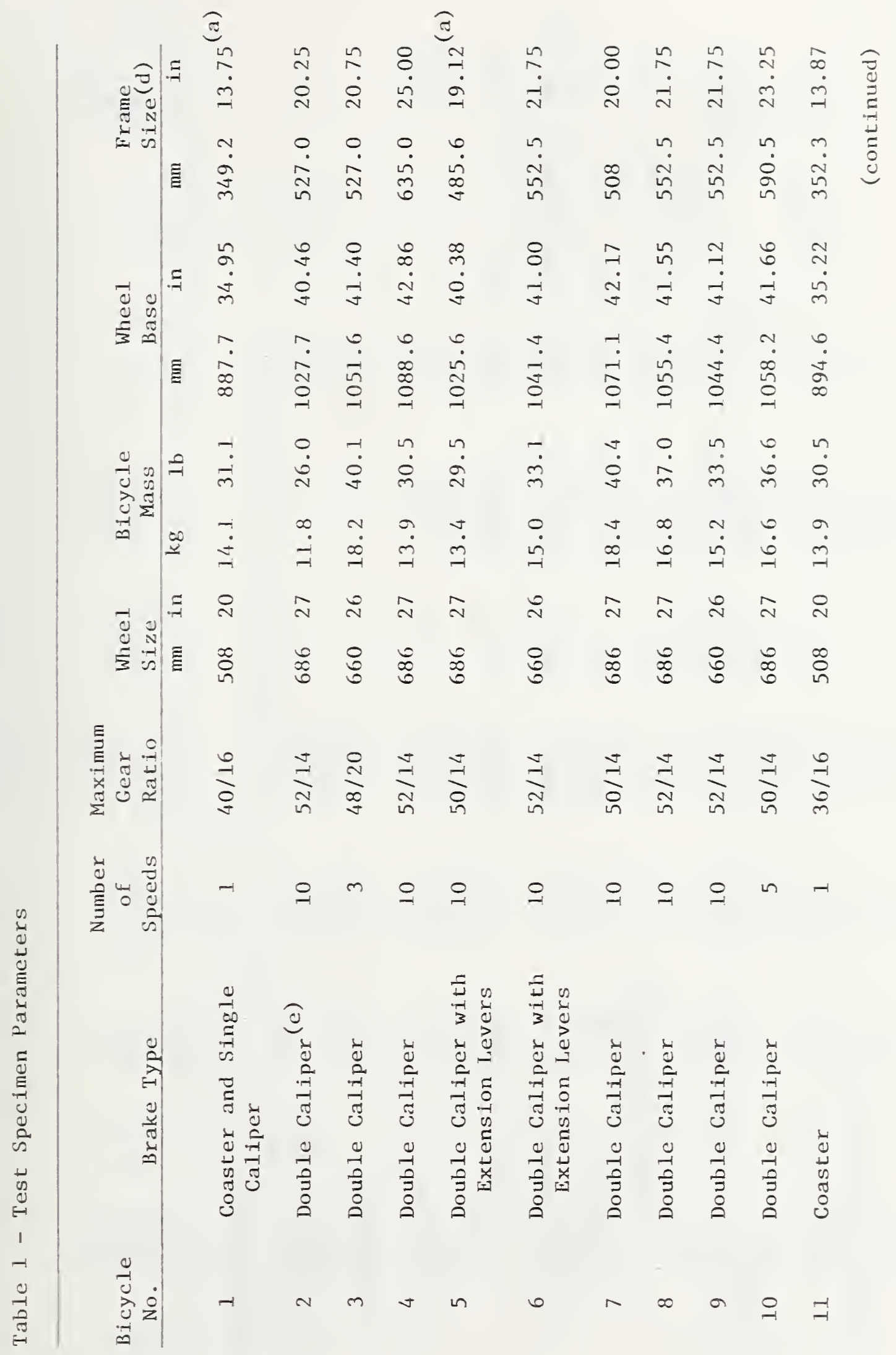




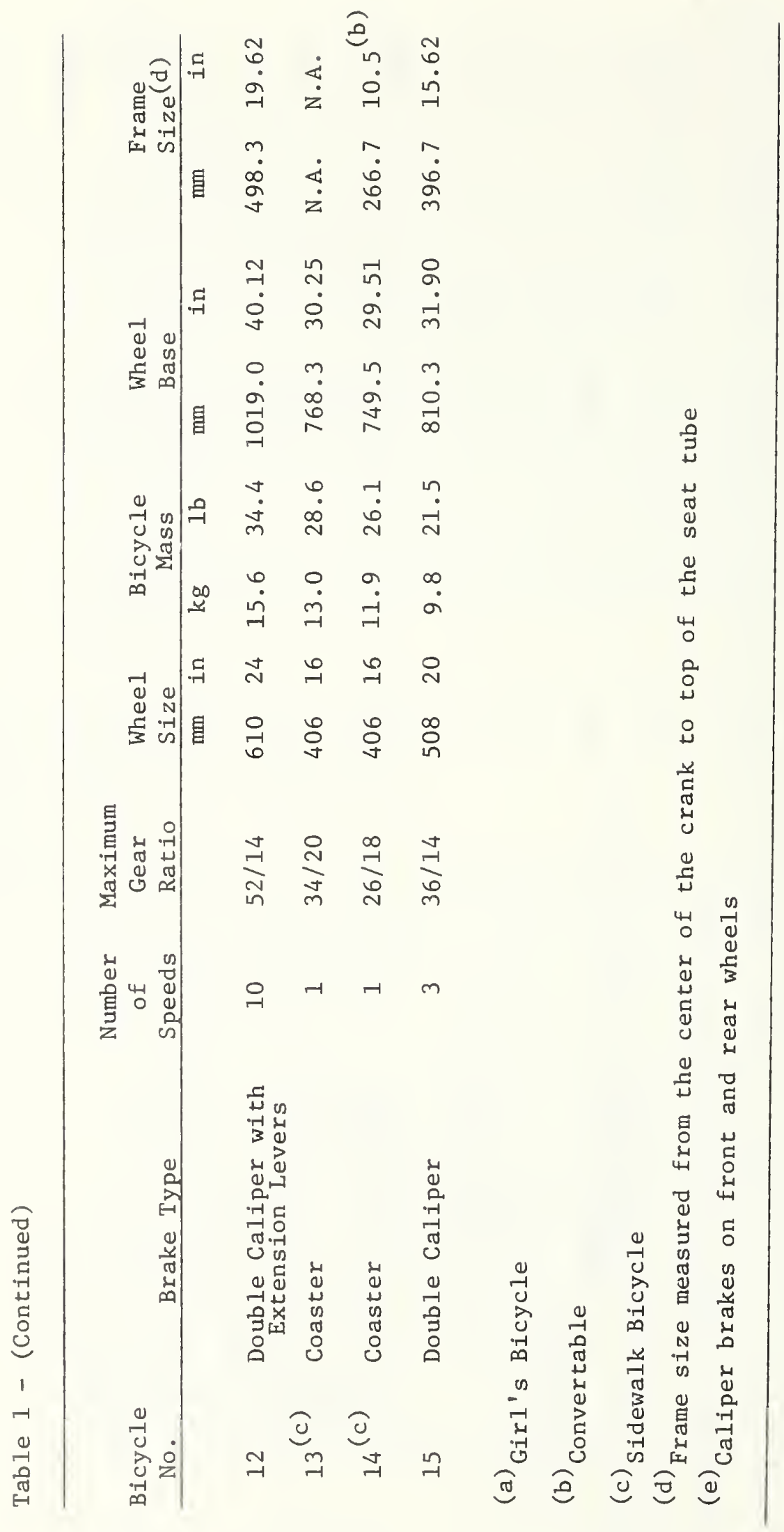




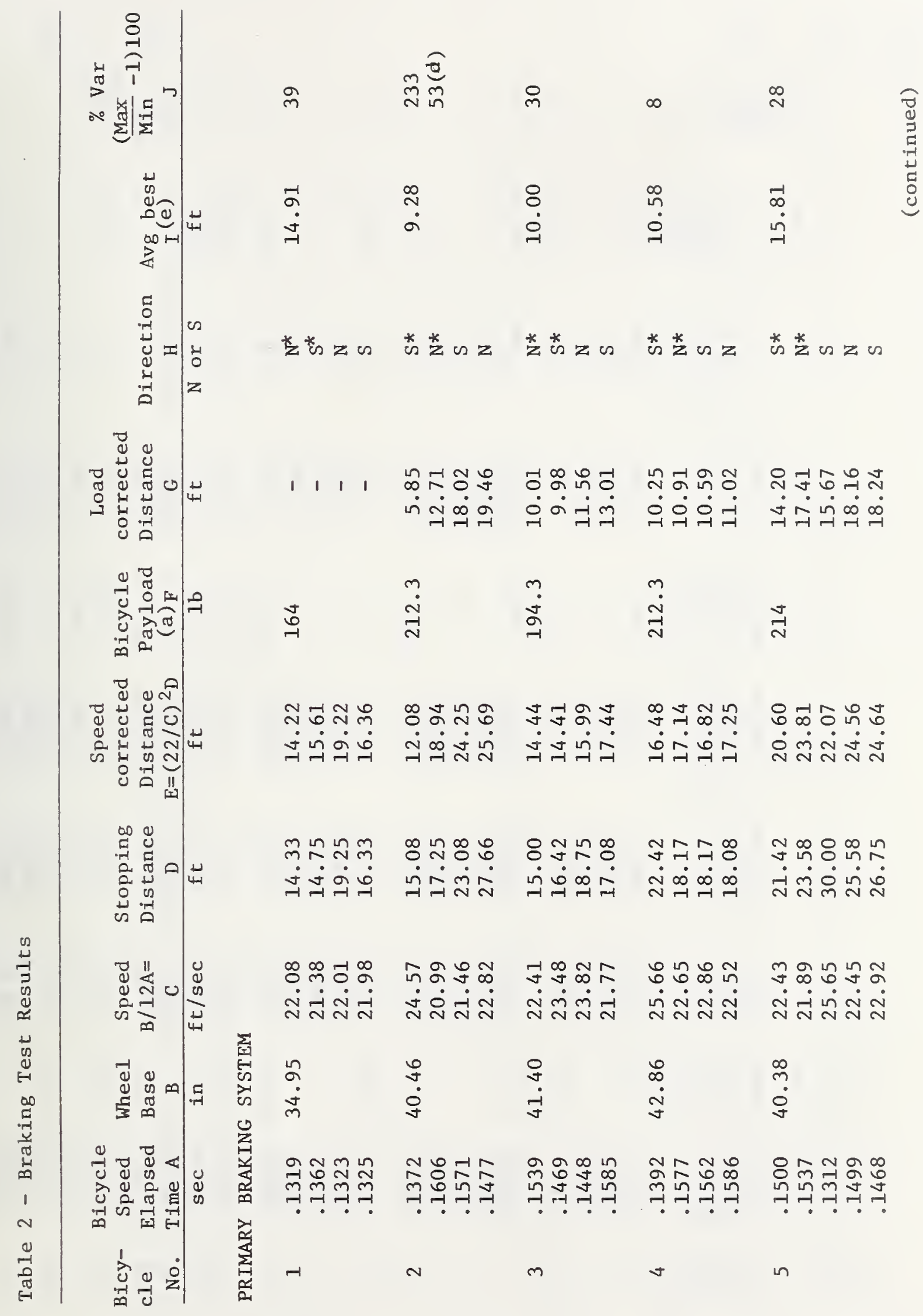




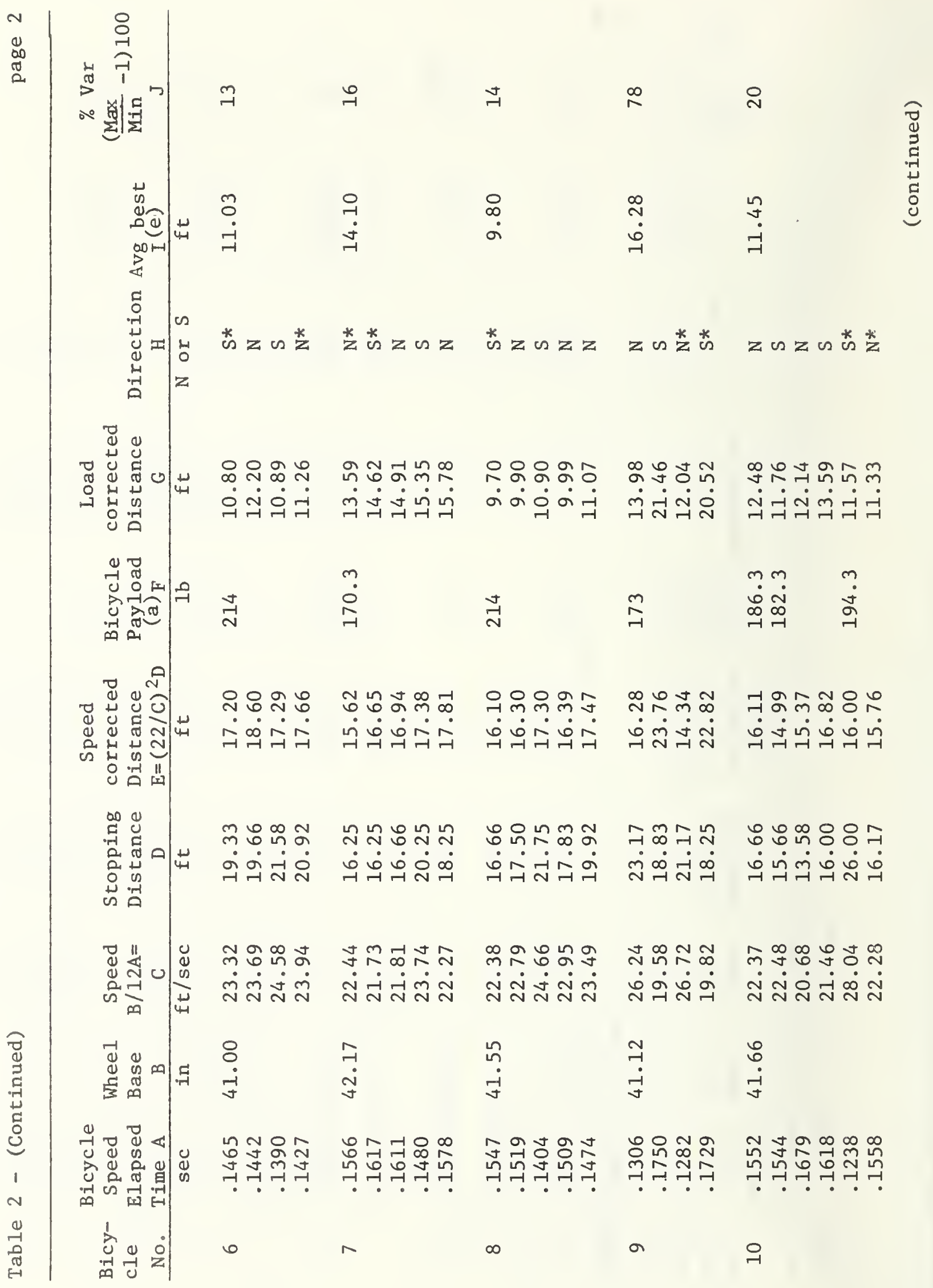




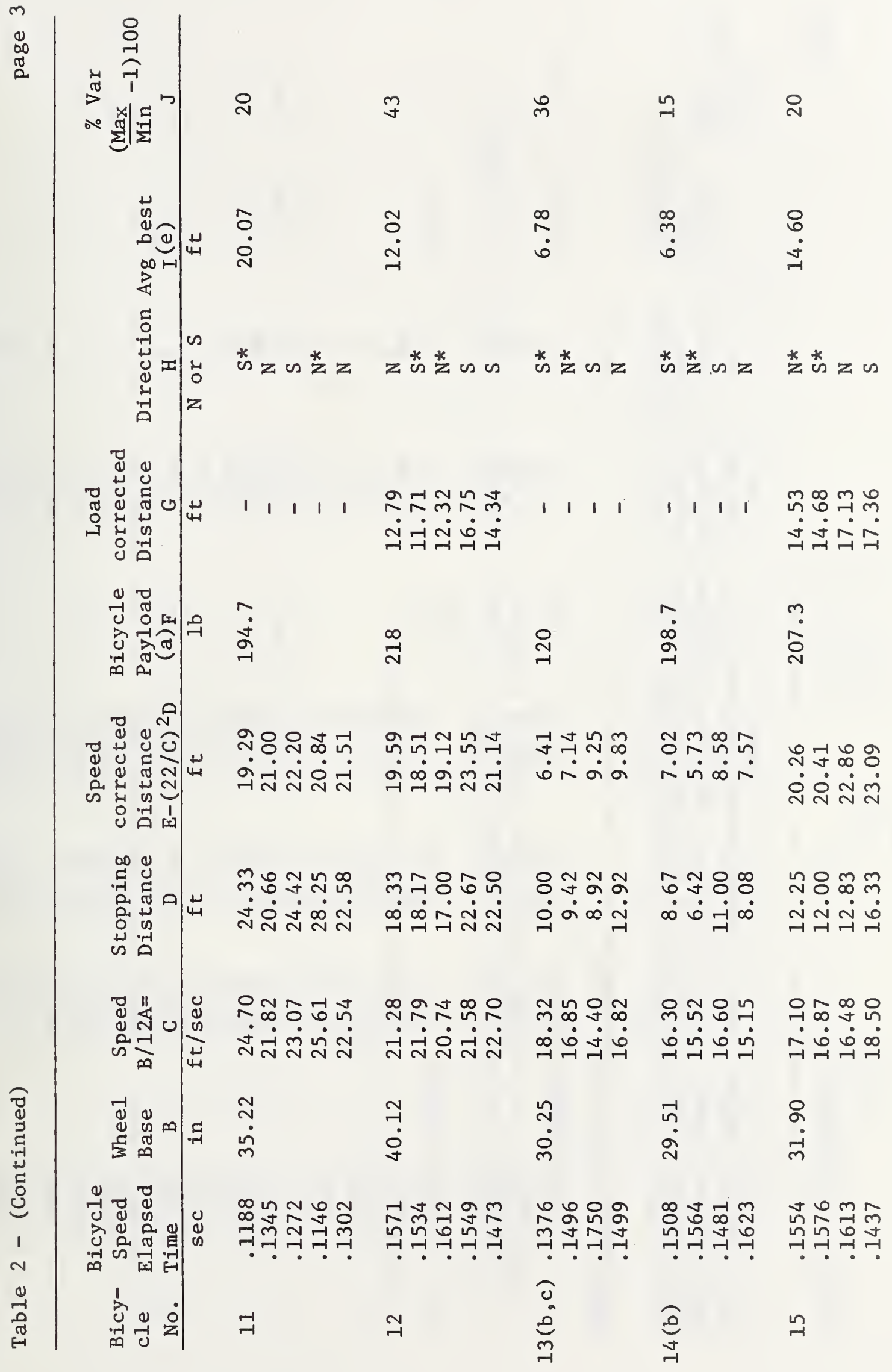




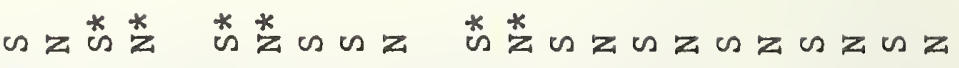

$\frac{1}{1}$

$\underset{-1}{\stackrel{-1}{*}}$

$\stackrel{0}{\circ}$

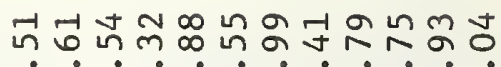

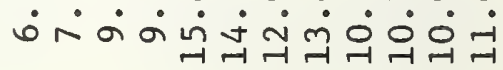

م

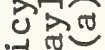

角<smiles>C1CCCCC1</smiles>

ra

ヘே

$\stackrel{n}{a}$

a

ชี

ช

॥ ब तิ

A $H+N$

$\begin{array}{ccc}4 & n & 1 \\ 0 & 0 & 11 \\ 0 & 0 & 11\end{array}$

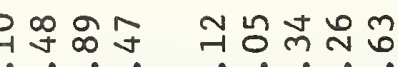
$\dot{0} \dot{\dot{0}} \dot{0} \dot{0} \dot{\sim} \dot{ }$

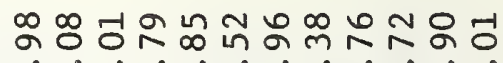

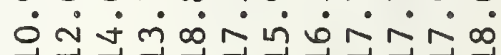

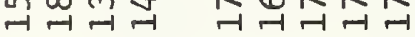

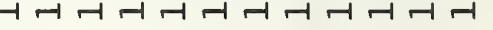

ㅇํำ ำำ

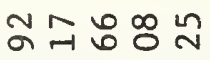

๒ย 당ㅇํㄹ

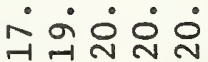
$\dot{n} \dot{\infty} \dot{0} \dot{0} \dot{-} \dot{\sigma} \dot{n} \dot{\sim} \dot{\omega}$

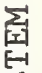

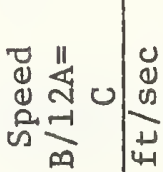

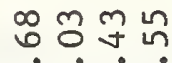

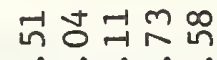

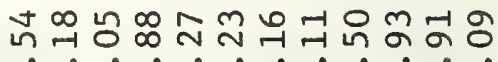
$\dot{n} \dot{\theta} \dot{n}$ $\dot{\sim} \dot{\sim} \dot{\sim} \dot{m}$ ป் ฟก่ั่ กัก

$\stackrel{\infty}{\mathfrak{m}}$

$\underset{8}{0}$

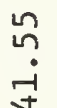




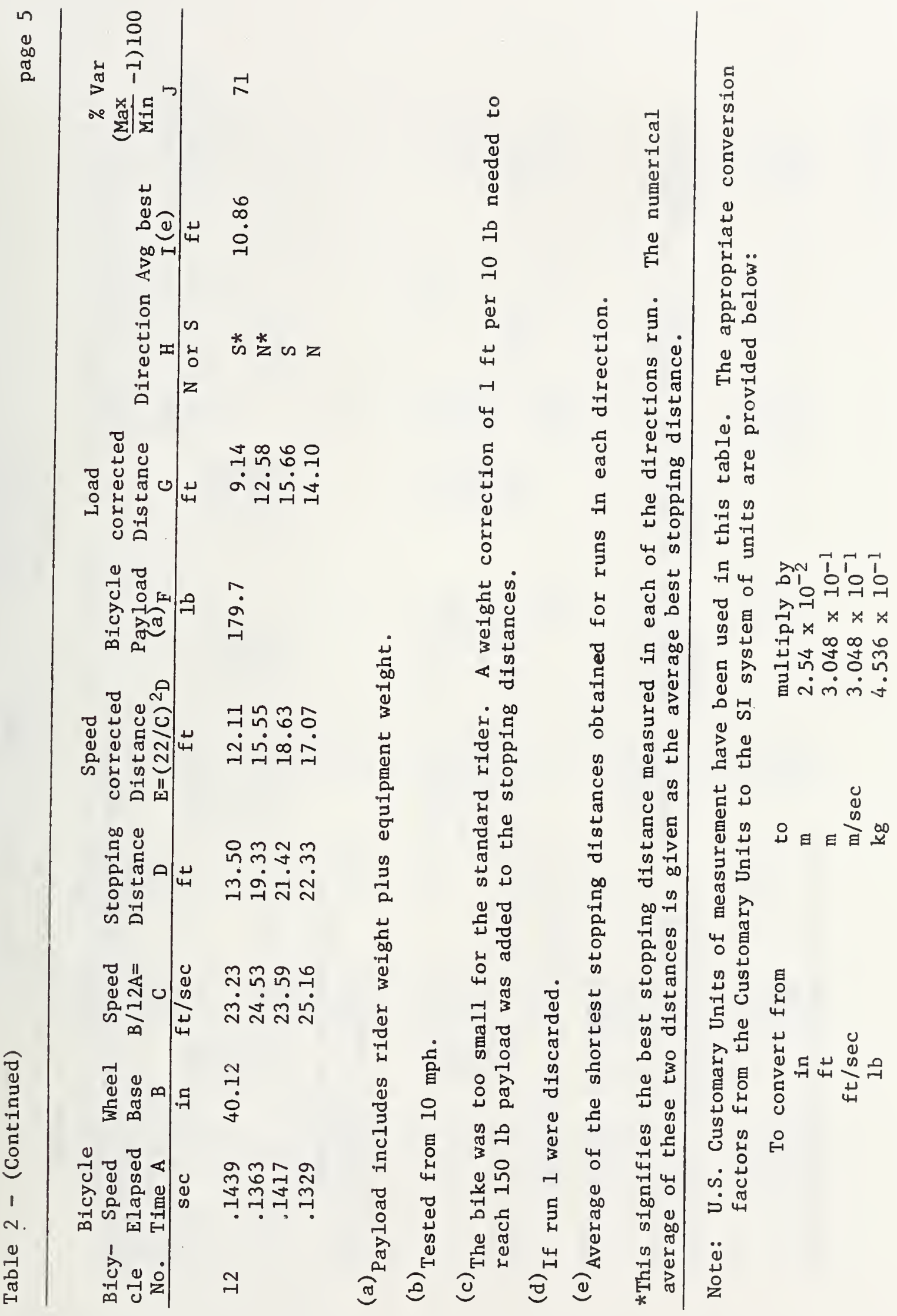




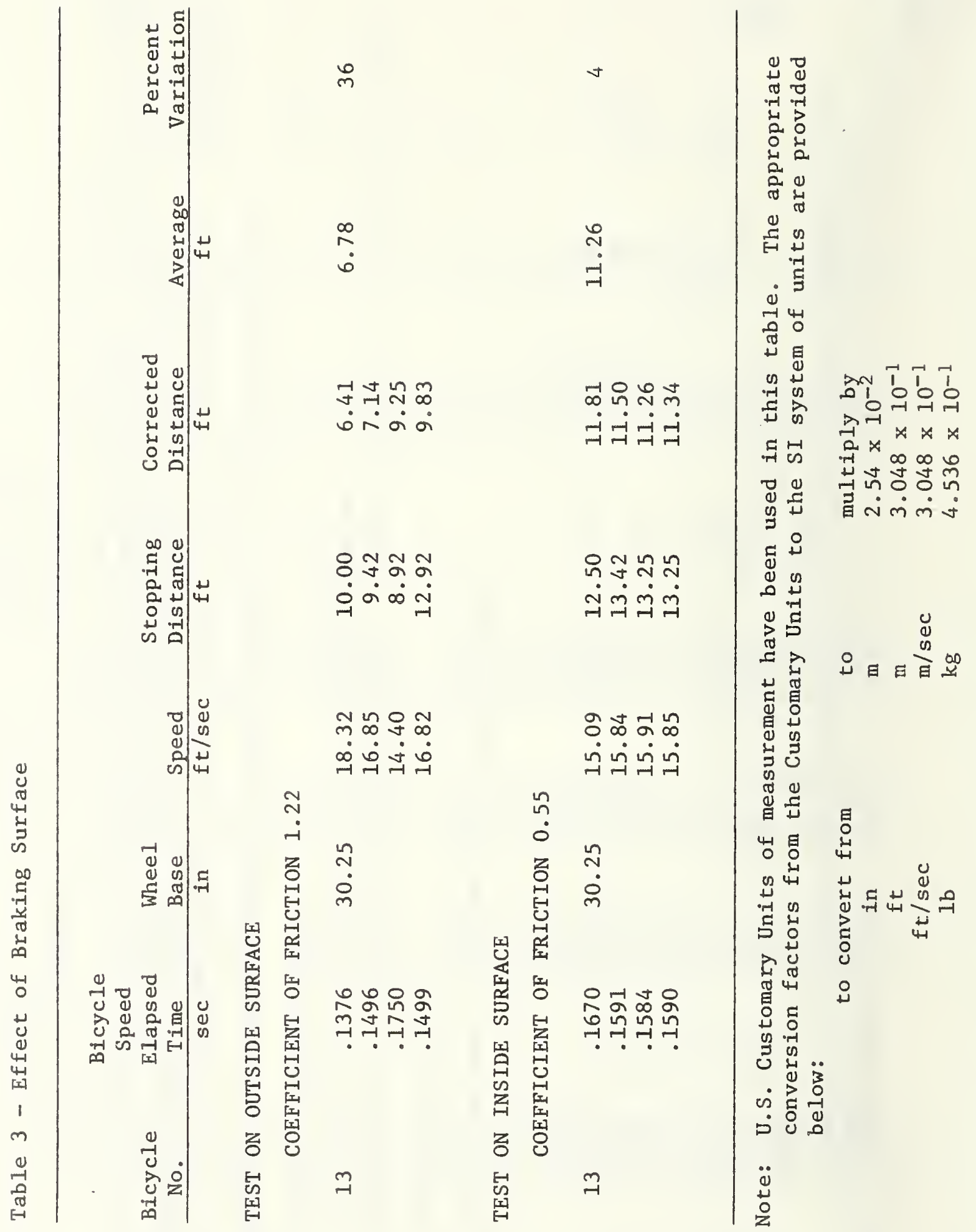




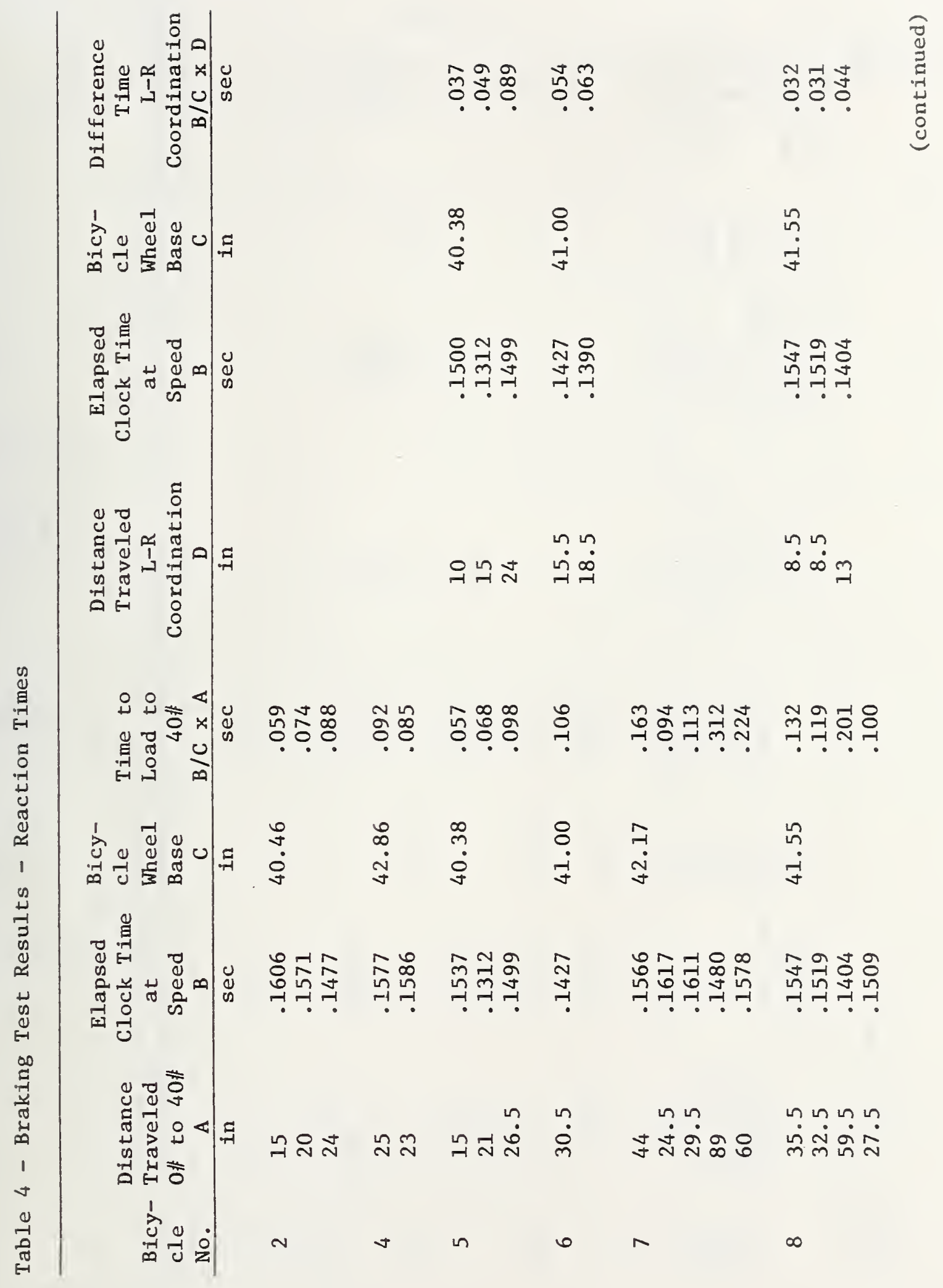




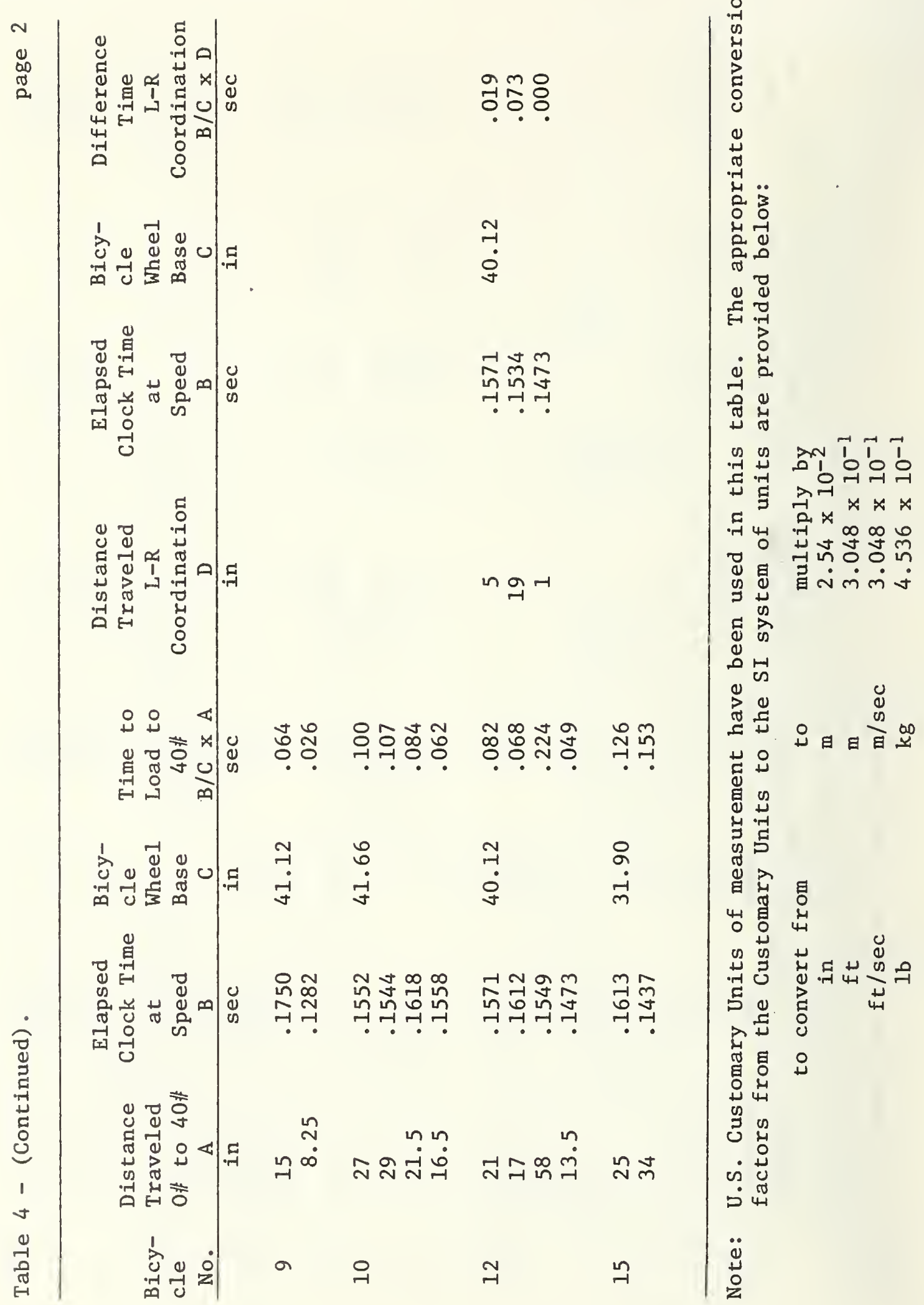




\section{APPENDIX}

This appendix contains the engineering drawings for the test fixtures designed for these tests and the parts list of all equipment used. 
NBS.I14A (REV. 7-73)

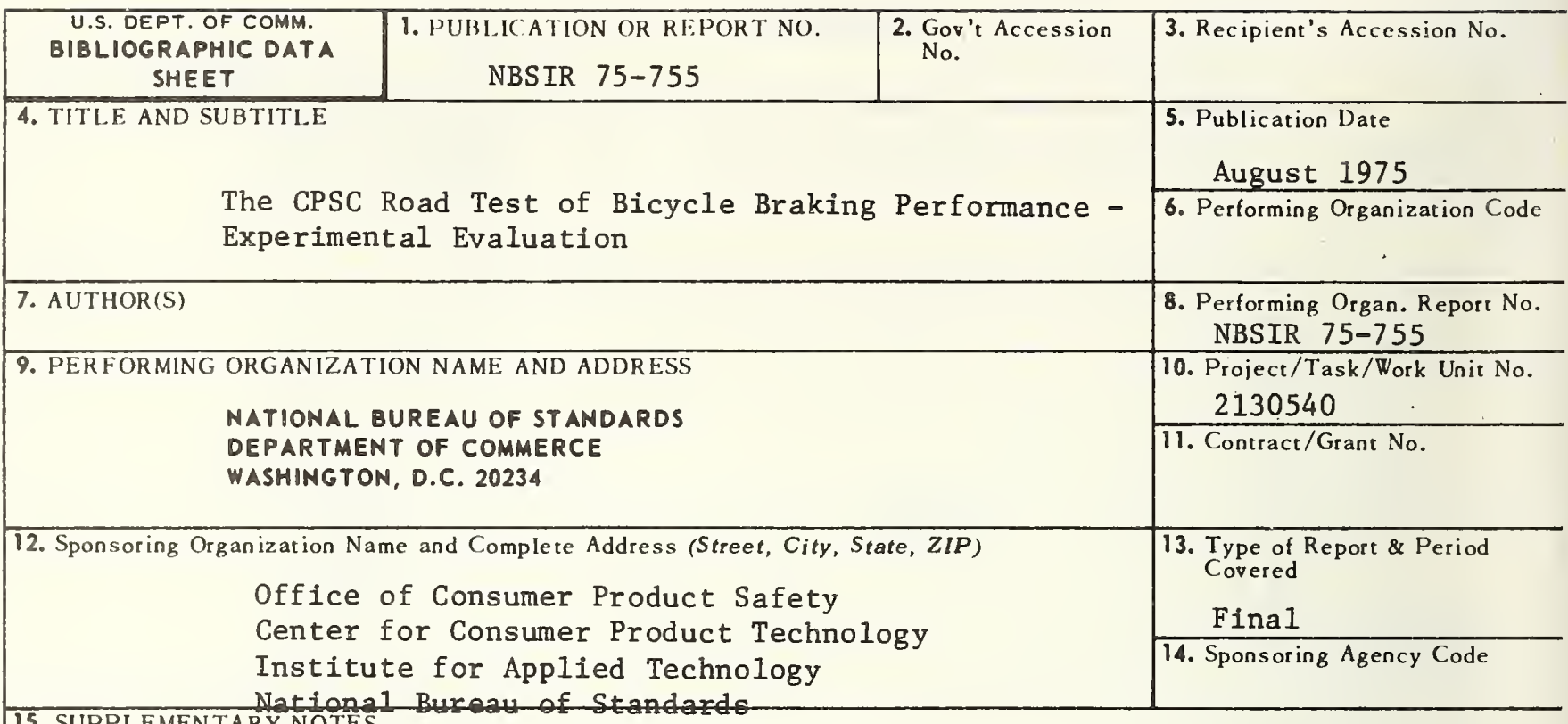

15. SUPPLEMENTARY NOTES

16. ABSTRACT (A 200-word or less factual summary of most significant in formation. If document includes a significant bibliography or literature survey, mention it here.)

The brake performance criteria to be published as part of a mandatory regulation on bicycle safety requirements has been evaluated. Fifteen bicycles were tested in accordance with the regulation. A mathematical adjustment of the actual test speed of the bicycle to $24 \mathrm{~km} / \mathrm{hr}$ ( $15 \mathrm{mph}$ ) is necessary before the weight allowance can be made to the stopping distance in the evaluation of these tests. A danger of injury to the test rider exists during the tests and future efforts shou be made toward replacement of these tests with a simpler laboratory procedure.

17. KEY WORDS (six to twelve entries; alphabetical order; capitalize only the first tetter of the first key word unless a proper name; separated by semicolons)

Bicycles; braking; consumer safety; handbrake; safety; testing

18. AVAILABILITY

For Official Distribution. Do Not Release to NTIS

Order From Sup. of Doc., U.S. Government Printing Office

Washington, D.C. 20402, SD Cat. No. C13

X Order From National Technical Information Service (NTIS) Springfield, Virginia 22151

\begin{tabular}{|c|c|}
\hline $\begin{array}{l}\text { 19. SECURITY CLASS } \\
\text { (THIS REPURT) } \\
\text { UNCL ASSIFIED }\end{array}$ & $\begin{array}{c}\text { 21. NO. OF PAGES } \\
32\end{array}$ \\
\hline $\begin{array}{l}\text { 20. SECURITY CLASS } \\
\text { (THIS PAGE) } \\
\text { UNCLASSIFIED }\end{array}$ & $\begin{array}{l}\text { 22. Price } \\
\$ 3.75\end{array}$ \\
\hline
\end{tabular}


$=$

1

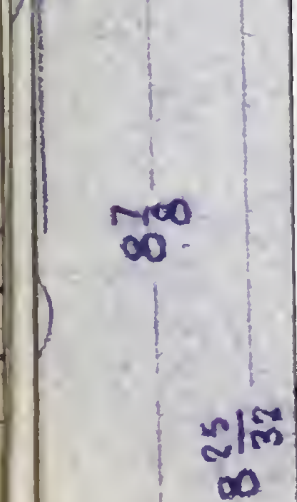




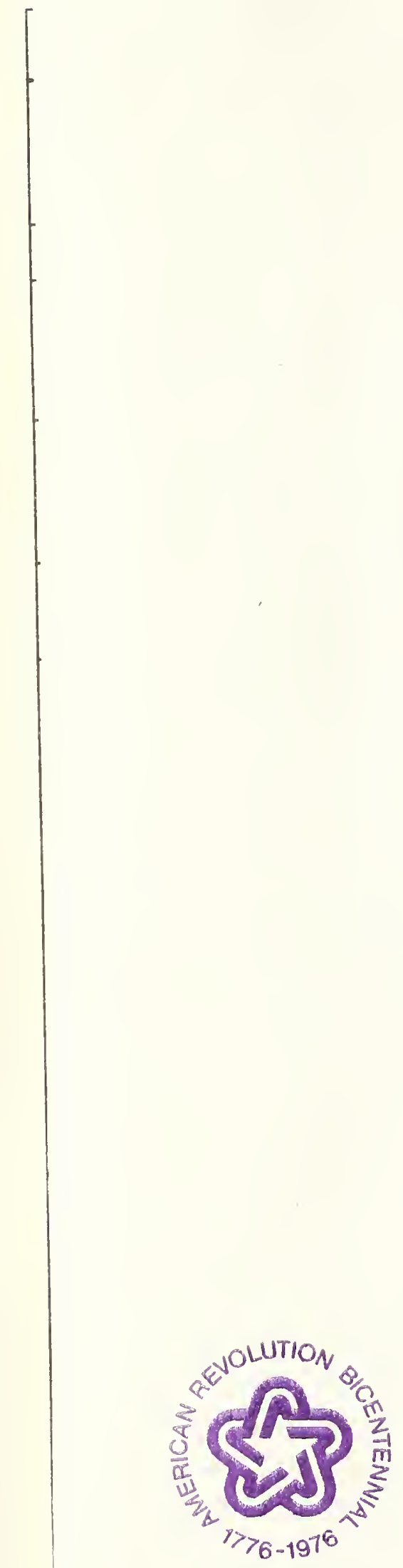

